\title{
Exploring Ethnic Stereotypes and Prejudice Among Some Major Ethnic Groups in Ghana
}

\author{
Victoria Wendy Lawson (Corresponding author) \\ Dept. of Psychology, University of Ghana \\ PO Box LG 84, Accra, Ghana \\ E-mail: vwlawson@ug.edu.gh
}

Charity S. Akotia

Dept. of Psychology, University of Ghana

PO Box LG 84, Accra, Ghana

E-mail: sakotia@hotmail.com

Maxwell Asumeng

Dept. of Psychology, University of Ghana

PO Box LG 84, Accra, Ghana

E-mail: maxasumeng@yahoo.com

Received: April 30, 2014 Accepted: July 4, 2014 Published: July 25, 2014

doi:10.5296/jsss.v2i1.5561 URL: http://dx.doi.org/10.5296/jsss.v2i1.5561

\begin{abstract}
Ghana as a heterogeneous country has many different ethnic groups living together in a unitary state. Naturally, these various groups are bound to hold diverse perceptions about one other. A typical example concerns people from the southern regions referring to individuals from the three northern regions as "northerners" and ascribing general characteristics to all of them as though they belong to one ethnic group. Using a qualitative method, this study explored the extent to which four major ethnic groups (Dagomba, Ga, Ewe, Akan) in Ghana generate and use stereotypes to describe themselves. Quota and convenient sampling
\end{abstract}


techniques were used to select 164 respondents from four major ethnic groups. Respondents were asked through open ended questions about the perceptions they hold about the group they belong to (in-group) and the out-groups. Thematic-content analysis of the responses indicated that stereotypes prevail among the four major ethnic groups. Each group held positive and negative stereotypes for both in-group and out-groups based on the level of contact. The findings are discussed using social identity theory and contact hypothesis.

Keywords: Ethnic groups, Stereotype, Prejudice, Social identity theory, Contact hypothesis 


\section{Introduction}

Ghana is a multi-ethnic country where various ethnic groups live together. Naturally, the many different ethnic groups are bound to hold diverse perceptions and bias attitude about one other through daily interaction and assessment. Whereas prejudice is understood to be a bias attitude towards members of a particular group, the knowledge, perception or information held about the group constitutes the cognitive component of prejudice, normally called stereotyping (Condor, 2006; Leeson, 2006). From such multi-ethnic nations, social scientists believe prejudice is the root cause of most conflicts. However, empirical studies have not explored the dynamics of stereotyping and prejudice among ethnic groups in Ghana. Among the various ethnic groups in Ghana are Akan, Mole-Dagbani, Ga-Dangme, Ewe, Guan, Gurma, Grusi and Mande (Ghana Statistical Service, 2012). Studies on prejudice and stereotype emanated from the western world and extensive focus has been on dominant group versus minority group bias. Findings from these studies show that prejudice and stereotyping persist in an inter-group relation and they arise in part from social categorization (Hornsey, 2008).

Social grouping or categorization as a prototype, organizes people who share similar characteristics in one category while dissimilar ones could be differentiated (Hogg \& Reid, 2006). The essence of categorization is to offer members in a group a social identity. Social identity as explained by Tajfel and Turner (1986) relies on the assumption that individuals have a basic need for positive self-esteem. The desire, as well as the search for the self-esteem could be derived from the group one affiliates. This becomes the tenet of social identity theory in understanding inter-group relations and group processes specifically hostile attitudes. Social identity formation involves two fundamental processes; self-categorization and comparison. These two important processes lead to different outcomes (Stets \& Burke, 2000). In a multi-ethnic context where several dominants groups do interact among themselves, would the findings of stereotyping among them differ from the existing studies? The purpose of this paper is in three folds. Firstly, to explore the extent to which four major ethnic groups in Ghana use stereotype to describe their in-group and out-groups. Secondly, the paper investigates the applicability of the social identity theory. The theory proposes that when group identity becomes conspicuous in the face of comparison, members of a social category are more likely to use positive attributes to characterize the in-group whilst using negative attributes for the out-groups. Finally, the researchers seek to examine the role of the contact hypothesis in explaining the behavior of these ethnic groups.

\section{Literature Review}

Current focus of research on inter-group relations investigates how self-categorization and group comparison could be used to explain and understand prejudice. For example, self-categorization causes a member of a social group to view the self as possessing certain qualities in common with other members thereby creating the in-group, whilst, looking out for other qualities that differentiate the self and other selves who belong to one social category from entirely others and this new group constitute the out-group (Barrett, Wilson, \& Lyons, 1999; Oakes, Haslam, \& Turner, 1994; Van Bavel \& Cunningham, 2011). Hence, 
when the self is placed in a social category, it spontaneously creates the "us" versus "them" which may lead to prejudice and stereotyping towards the out-group. This is revealed in Condor's (2006) qualitative study, where people's use of derogatory words defines others in the course of their conversation. Condor's study did find that public expression of racial prejudice involve collaborative accomplishments.

Social comparison on the other hand is based on evaluation of inter-group interaction. To make the self feel "good" the individual uses positive attributes to describe the in-group so that the out-group receives the unfavourable treatment (Castano \& Yzerbyt, 1998; Condor, 2006; Gordijn, Finchilescu, Brix, Wijnants, \& Koomen, 2004; Kawakami et al., 2002; Leeson, 2006; Nakamura, 2009; Tajfel et al., 1971). For instance 'if my group is rated better, then it means I am good'. Gordijn et al. (2004) found in their study that prejudice was related to perception of a more negative cultural stereotype of out-group and perception of a more positive meta-stereotype of one's in-group. The negative feeling towards others was as a result of the bond in-group members feel with their identity. This result was so for only dominant group, so, Gordijn et al. concluded that prejudice predict negative than positive feeling. The negative feeling of prejudice can consequently lead to negative outcomes. An implication of such negative stereotyping and ethnocentrism is seen in Khanlou et al.'s (2008) study where Afghanistan and Iranian youth in Toronto hid their identity. From these studies, it is apparent that there is a relationship between social grouping and prejudice as well as stereotype.

However, it is evident that how an individual identifies with the in-group brings about the bias attitude toward an out-group (Oakes, 2001). Studies have explored the identification process using the contact hypothesis. The contact hypothesis is used to explain inter-group behavior (Pettigrew, 1998). Here, in-group members who interact with out-group members are less likely to hold negative stereotypes about them. Though there are instances where more contact have led to more conflict. Notwithstanding this, the theory still has relevance in understanding group behavior. Pettigrew and Tropp (2006) did an extensive and insightful review of the phenomenon and found that contact with out-group leads to a relatively small reduction in prejudice, however the change is reliable. This study explains the contact hypothesis with reference to groups having knowledge, living with and identifying with the groups they do not belong.

\section{Method}

\subsection{Research Questions}

Given the background that Ghana is a multi-ethnic nation, the paper seeks to address the following research questions,

1. To what extent do individuals use stereotypes to describe their in-group and out-group or how do individuals perceive their in-group and other groups (out-groups)?

2. Does ethnic group identity influence stereotype generation? 
3. Does the level or frequency of contact a person has with his or her in-group and out-groups influence his or her stereotype generation?

\subsection{Participants}

The population of study comprised males and females of age above 18 years from Dagomba, $\mathrm{Ga}$, Ewe and the Akan ethnic groups. These four ethnic groupings in Ghana were chosen because the 2010 population and housing census showed they are the major ethnic groups in Ghana. Specifically, the report on the 2010 population and housing census shows that $47.5 \%$ of Ghanaians are Akans, $16.6 \%$ are Mole-Dagbanis, 13.9\% belong to the Ewe ethnic group and $7.4 \%$ identify as Ga-Dangme (Ghana Statistical Service, 2012). The Akan as the largest ethnic group in Ghana comprises Asante, Fante, Denkyira, Akwamo, Akyem, Bono, Kwahu, Sefwi, Ahafo, Assin, Wassa, Nzema and Akuapem sub-groups. These sub-groups are predominantly found in the Ashanti, Eastern, Western, Central and Brong Ahafo regions of Ghana. The Ewes are located at the Volta region of Ghana, the Dagombas are found in the Northern region whilst the Gas are in the Greater Accra region. This study was accordingly conducted in the Greater Accra, Ashanti, Northern and Volta regions of Ghana where the ethnic groups are predominantly situated. Though, both quantitative and qualitative data were collected, only the qualitative is reported in this paper. Quota and convenience sampling techniques were used to select 240 participants. A total of 164 respondents completed the open ended questions. This comprises 47 Dagombas (13 males and 34 females), 39 Gas (19 males and 20 females), 20 Ewes ( 8 males and 12 females) and 58 Akans (28 males and 30 females).

\subsection{Procedure}

To address the research questions, a qualitative research methodology was employed. Through open ended questionnaire, respondents were asked to describe how they perceive their own ethnic group as well as the out-groups. Specifically, they were asked the following questions;

1. how do you perceive or think about your ethnic group?2. how do you perceive or think about your out-groups?

Also, respondents were to indicate by ticking the frequency of contact they have with both their in-group and out-groups based on their daily interaction with the specific ethnic groups. Here, is the instruction given: "Please choose from the following 1-4: no contacts (1), less often (2), often (3), very often (4) to indicate your level/ frequency of contact with your ethnic group and your three out-groups. For example if Akan is your ethnic group, then Ga, Ewe and Dagomba are your out-groups. Contact here means interaction with people within and outside your own ethnic group through marriage, friendship, working with, or colleague from school".

The researchers with the research assistants travelled to the four chosen regions for the data collection. On arrival at each region, the team moved from house to house and it was introduced by a team member who speaks, reads and writes the native dialect. The research was explained to the respondents and their verbal consent was sought before they were 
allowed to participate in the study. Data was collected from January to April 2012

\subsection{Data Analysis}

Data was analyzed using thematic-content analysis (Miles \& Huberman, 1994). The framework involves three concurrent flows of activity: data reduction, data display and conclusion drawing/verification. In the data reduction stage firstly, the researchers read through all the survey and grouped the completed or filled questionnaire from the unfilled ones. Out of the 240 respondents, 164 completed the open-ended questions and this number was used for the analysis. A table was developed to organize the data by typing verbatim what each respondent said about the in-group and out-groups. Here, the focus was on categorizing how individuals perceive their in-group and out-group. Secondly, the organized responses were further broken into phrases or words as codes. Using the research questions as guide, the researchers utilized the Apriori codes to find patterns in the textual data. Several codes were generated from the text and among them are compassionate, generous, sociable, accommodative, peaceful, honest, humorous and selfless. These codes were categorized as human values, which became a sub-theme. Other sub-themes were also generated and the related clusters were further reduced into positive and negative stereotypes. In summary, through the coding stage, sub-themes emerged which led to major themes (see appendix). The data display involves organizing the themes and sub-themes into a conceptual model which represents the in-group and out-group stereotype among the four ethnic groups. Finally, explanations were given and conclusion was drawn from the model.

\subsubsection{Reliability/Trustworthiness and Validity of the Data Analysis}

The subjective nature of qualitative analysis makes the trustworthiness of findings questionable. However, validity and reliability are assessed to make findings acceptable. Validity deals with the credibility of qualitative data. Maxwell (1992) explains three types of validity and they are descriptive, interpretive and theoretical. Descriptive validity is the reporting of accurate data by the researcher. The researchers therefore typed verbatim the words, phrases and statements of respondents which were used for the analysis. In addressing the interpretive validity of the data, the researchers reported the accuracy of interpretation pertaining to the perceptions of respondents about the in-group and out-group. Finally the theoretical validity which is concern with how conclusion drawn is congruent with the data was ensured. To do this, the researchers used the transcribed data, reduced data and the themes generated to verify the conclusion of the data. Also, the researchers went back to 20 of the respondents asking them whether the data used was in line with their perceptions of the in-group and out-group. The responses affirmed the findings of the data and the technique is termed as member checking by Newman and Benz (1998). The authors have outlined several other ways to enhance internal validity of a qualitative data which include peer review, low inference descriptors and audit trail. For instance an in-group member writes of the out-group "They are filled with pride and mostly ethnocentric". Here pride and ethnocentrism were coded. This technique of ensuring validity, termed low inference descriptors was followed. 


\section{Findings}

We report findings of how ethnic stereotypes were generated by participants according to norms for reporting qualitative study. The respondents' perception of their ethnic group (in-group perception) and out-groups (out-group perception) were broadly categorized into positive and negative stereotypes. These stereotypes are further discussed under in-group perception and inter-group perception.

\subsection{In-group Perception}

In-group perception in this context means how ethnic group members perceive their own ethnic group. Generally, both positive and negatives stereotypes were used to describe in-group members and discussed below.

\subsubsection{Positive Stereotypes}

Positive stereotypes are the favorable qualities or attributes that in-group members think are typical of their group and thus used to describe them. Three sub-themes were generated under the positive stereotypes for the in-groups. The sub-themes are human values, culture and power and work ethics. The positive stereotypes were mostly used by individuals who identify more with the in-group and have less contact with out-groups.

\subsubsection{Human Values}

The human values were based on how generous, hospitable, compassionate, humble and sociable in-group members are. For example:

...I think members of my clan are compassionate, caring, loving and relate well in public in terms of responding to critical issues (male, 33).

...My group is hospitable and often willing to help people (male, 40).

... My ethnic group members are friendly, honest, encouraging and understanding (female, 29).

From the above, it is evident that positive human values characterize the description of in-group members.

\subsubsection{Culture and Power}

Another sub-theme that was generated was 'culture and power'. Respondents proudly talked about their rich culture and how powerful their ethnic groups are. These sayings were to demonstrate their unique way of life and the authority they each believe to have. For example:

... I see my ethnic group to be one of the best, because we are proud of our culture and tradition (male, 37).

... My ethnic group members are powerful, unique... (female, 48).

The various ethnic group traditions and norms are highly respected by in-group members, 
which they think are attributes that are worthy to be generally characterized with.

\subsubsection{Work ethics}

Informants also held the belief that members from their ethnic groups possess good work ethics. For instance:

... My ethnic group is creative and hardworking (male, 26).

... They are very hard working people... (male, 35).

It is not only human values and culture that in-group members use as positive stereotypes for the ethnic group. In-group members also perceive their ethnic group to be dedicated and loyal to their jobs.

\subsubsection{Negative Stereotypes}

Though positive stereotypes were used to describe in-group members, negative stereotypes were also used by some in-group members. This was usually the case when in-group members indicate that there was less contact with the in-group and more contact with out-groups. For example stereotypes such as "unfriendly, proud, greedy, lazy, aggressive and impatient" were used by respondents who had less contact with the in-group. A respondent who identify highly with the in-group and has very often contact with some members of the out-groups had this to say,

...As much as I love my ethnic group, I have certain reservations, that is most of the men tend not to like work and most often are very irresponsible. The women are really hard working and most of them tend to be single mothers and only few of them tend to love education. The educated women tend not to be interested in marrying Ga men (female, 27).

This informant accepts adoring the ethnic group but that does not influence the perception being held about the in-group. Perhaps interactions with out-group members have made her to describe the in-group with no bias. It could be deduced that the group that one belongs to does not bias the perception of in-group members as explained by social identity theorists.

\subsection{Out-group Perception}

Out-group perception in this context means the attributes that three ethnic groups think are typical of the fourth ethnic group. For instance, it captures how respondents who are Akan, Ga and Dagomba expressed their perception of Ewes. In all, four target out-groups emerged. Thus three in-groups perception about one out-group based on the positive and negative stereotypes were also categorized.

\subsubsection{Positive Stereotypes}

The positive stereotypes are favorable attributes three ethnic groups think mostly describe a target out-group. Using Akan as a target out-group the positive stereotypes held by the three ethnic-groups about them were more than the negative perceptions. These groups perceive Akans as hospitable, creative, responsible, sociable, and business oriented and trustworthy as positive stereotypes. For example: 
...They are very hospitable and like to do business a lot.... (female, 55).

...They are very courageous, hardworking and industrious. Extremely curious and creative, very business oriented... (male, 30).

The Dagombas, Gas and Akans also described what they think about Ewes, their target out-group. Responses indicate that they believe Ewes are intelligent, hardworking, respectful sociable and they love education.

...As for them (Ewes), they don't take chances with their education. In fact they always want to go to the top of education ... (female, 33).

The Gas also became the target out-group for the three in-groups Dagomba, Ewe and Akan and these few quotes could be used for demonstration of how they were perceived:

...They have peace and understanding and also take good care of out-groups... (female, 28).

...They love people and entertain strangers especially to do business (male, 30).

Lastly, Dagomba was the target out-group for Ga, Ewe and Akan where their perception was also gathered.

... They are not usually the kind of group I come across but then they seem to be a group who are unique especially their women are seen to be very hardworking (female, 24).

\subsubsection{Negative Stereotypes}

In as much as respondents expressed positive perceptions about the out-groups, they also exhibited their negative perceptions. Negative stereotypes were also used to describe out-groups. These include words such as lazy, aggressive, proud, unfriendly, loud and quarrelsome. The following are few quotes for illustration:

...As for the Akans, ...they are too proud and love money too much and also too knowing... (male, 30).

...The Ga men are lazy people and like boxing which makes them aggressive... (female, 27).

...I see the Ga people as also friendly but when it comes to an issue of marriage they sometimes discriminate. Also, I see the Ga people who also discriminate when it comes to accommodation (rent)... (male, 35)

\subsection{Role of Frequency of Contact}

We explored the role of frequency of contact with both in-group and out-group and how that could explain the type of stereotype use to characterize an ethnic group. Using the frequencies described under the procedure, in-group members' level of contact with their own ethnic group was categorized as well as the out-groups. We found that contact indeed helps to understand stereotype generation among the four ethnic groups. The positive stereotypes held about an out-group were mostly based on the frequency of contact with the group. Individuals may hold negative perceptions about others but as they interact with others and likewise climb higher on the educational ladder the perception could change. An Akan respondent's 
perception of Ewes changed and this is illustrated below:

...Being fair with you when I was at my lower levels of education I tend to believe all the negative stereotypic views of them like being witchcraft, juju and greedy minded people. Now base on me being close to them and the level of my education, my views about them have changed from worse to better and I tend to see them much more in a positive light (male, 26).

\subsection{A Conceptual Model of Ethnic Stereotypes among Four Major Ethnic Groups in Ghana}

The data display shows how frequency of contact with in-group and out-groups leads to generation of stereotypes among the chosen ethnic groups.

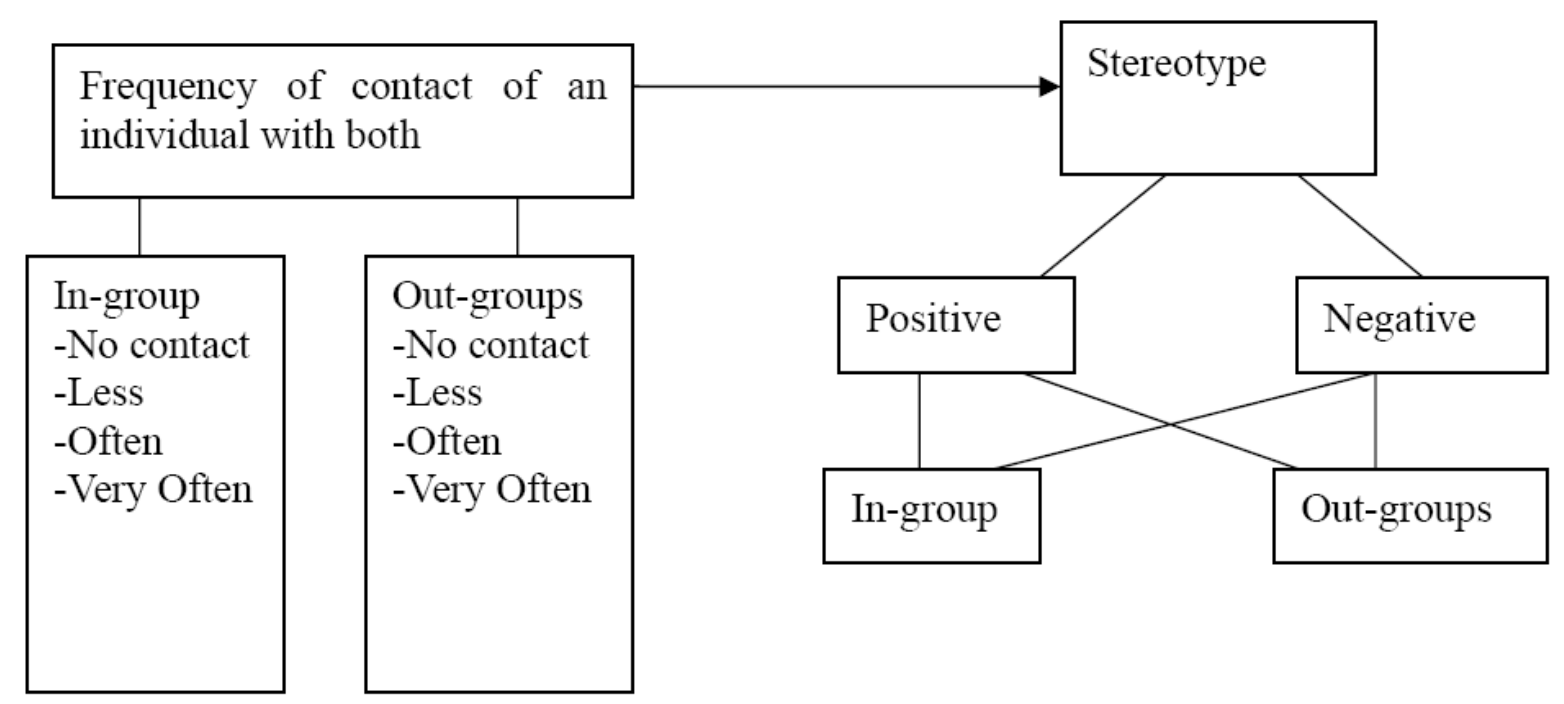

Figure 1. Conceptual/theoretical model of in-group and out-group stereotypes among four ethnic groups in Ghana

The conceptual/theoretical model shows the analytical explanation of how stereotypes are developed among four ethnic groups in Ghana; frequency of contact, stereotypes and their consequent components. The central proposition, frequency of contact and group membership leads to stereotype. We drew the following from the model:

1. An individual may have no contact with the in-group and no contact with the out-groups. However, such a combination was not found in the analysis. Some probable combinations like an in-group member having less contact with the in-group and either no, less, often or very often contact with the out-groups were found.

2. In-group members who had no or less contact with their ethnic group but very often contact with out-groups were more likely to use positive stereotypes to describe the out-groups than in-group members who had very often contact with the in-group and no or less contact with the out-groups.

3. The stereotype held about an in-group or out-group could be both positive and negative 
From the data displayed above, frequency of contact facilitates the kind of stereotype that is used to describe both the in-group and out-group

\section{Discussion}

\subsection{Perception of Individuals About Their In-Group}

When individuals categorize themselves in groups as found among the four ethnic groups, spontaneously, similarities and differences among the groups become obvious by each group members. These variations are known by group members because they belong to the group and may have to an extent some kind of interactions within the group (Hogg \& Reid, 2006). From this proposition, respondents who have daily interaction with members of their ethnic group were asked about their perception of their groups and the out-groups. Grounding the responses in line with the social identity theory, we anticipated that in-group members would use positive traits to describe the in-group while ascribing negative stereotypes to the out-group. This anticipation was confirmed in the study. The social identity theory proposes that individuals desire to enhance the image of the self (Tajfel \& Turner, 1986). Since their group gives them a sense of an identity, in an inter-group situation where they are required to compare their in-group with salient out-groups, the probability of using positive attributes to qualify the in- group members whilst using negative attributes for the out-groups is very high. Researchers like Castano and Yzerbyt (1998) Kawakami et al. (2002), and Gordijn et al. (2004) examined ethnic identification and how it explains in-group bias through stereotypes. In Kawakami et al.'s study, it was unfold that when people are allowed to express stereotypes openly and without negative consequences from others, it produces greater subsequent stereotype by those who were high on sexist. This implies that the higher one identifies with a group the more stereotypic ideas held about out-groups. To an extent, the finding of the thematic-content analysis is consistent with the above studies. Thus members who identified more with their ethnic group used positive traits to describe their in-groups whilst negative traits were used to qualify the out-groups. Positive attributes where used to characterize the in-group because according to the social identity theory, when individuals in an inter-group situation are allowed to compare their group and other groups, the tendency to see the in-group in positive ways is fundamental. The favorable social comparison simply enhances the self which makes it feel good. Thus if the group "I belong is good, then I am good because I am a member."

Aside the positive stereotypes that we expected to be used for in-group members clarifying ethnic prejudice, some in-group members used negative stereotypes to characterize themselves. Negative stereotypes which were used on the in-group where mostly from individuals who had less or often contact with the group and more contact with the out-groups. This means that it is not only ethnic identity that predisposes group members to hold negative stereotypic beliefs about the out-groups but daily interaction with out-groups help in-group members to hold positive for the out-groups.

\subsection{In-group's Perception of Out-groups}

It is natural for in-group members to see the out-groups in negative ways because the 
members want to enhance their group identity by comparing their groups with only positive stereotypes as postulated by the social comparison component of social identity theory. However, the dynamics of stereotypes in Ghana is quite fascinating because the usage of positive attributes is not limited to only the in-group but the out-group as well. The themes that were generated from the study revealed this assertion; however, majority of the respondents used positive stereotypes to describe the in-group. Both positive and negative attributes were used to describe the out-groups. This could mean that the perception of in-group about the out-groups depends also on the level of identification each group member has with the in-group. The result of the study confirms a study done by Leeson (2006) in the Australian context. Leeson allowed participants to come out with generated attributes they believed were typical of the average Australian. His study has disclosed that Australian identity was unrelated to prejudice. This result is contrary to the social identity theory predictions, meaning group identity alone does not predict in-group bias but it is how one identifies with the group. The identification process is explained using the contact hypothesis which helps to reduce prejudice. For instance, in-group members who have a lot of interactions such as living in an out-group community, schooling with, and attending religious practices out-group members but have less or often interaction with the in-group are more likely to use positive stereotypes to qualify the out-group. The emphasis therefore becomes essential to explore activities that relate to interaction or contact with both in-group and out-group. Could the collectivist nature of the Ghanaian culture have a role to play in this finding of the study? Though the researchers did not explore this, it is highly possible. As members of several distinct groups live together in a unitary country where there is interaction among them, the tendency to create bigger category beyond ethnic groupings becomes necessary to accommodate the variations among the groups. When this happens individuals within each group one way or the other live with other individuals in the same community, work at the same place, school together, and not forgetting inter- tribal marriages. This likely interaction influences the perception members hold for each other.

\subsection{Theoretical and Social Implication of the Study}

From the analysis of the study, ethnic grouping is a key facet when discussion stereotyping. However, the kind of stereotypes held of a group is not only base on ethnic identity as proposed by social identity theory but on the frequency of contact. Thus, the level of interaction individuals have with both in-group and out-groups is equally important in understanding ethnic stereotype and prejudice. This means that individual differences within an ethnic group could also help to understand ethnic prejudice. The social identity theory is confirmed where each ethnic group members used negative stereotypes to qualify the out-groups. The departure is where more frequency of contact with out-groups influence the kind of stereotype used on the in-group. Individuals do interact among themselves though they belong to different ethnic groups. This is due to the Ghanaian cultural orientation where individuals unify all the smaller ethnic groups under one big social category and they act in ways that conform to the cultural norm than to the ethnic group's values. So, the social identity is not in reference to the ethnic group but to the nation in which they dwell. From this perspective, re-categorization should be of major concern to government where school 
curriculum is structured to teach students of diversity and how it can facilitate national development. Also future researchers should explore how re-categorization can help to integrate various distinct ethnic groups to promote national unity.

\subsection{Limitations of the Study}

One limitation was that some of the respondents found it difficult identifying the Dagombas. This is so because the three northern regions of the country are seen and categorized as one group bearing the northern identity. For instance a respondent answered "I know northerners to be aggressive so I think Dagombas are too". Though Dagomba is one of the major ethnic groups in Ghana, the northern identity supersedes it, hence, most respondents could not give a true perception they hold about Dagomba ethnic group. Majority of the Ewes though agreed to participate in the study, where not comfortable describing their perception of the in-group and other out-groups which led to a low response rate.

It was unfortunate all members of the chosen ethnic groups did not have equal chance of participating in the study since convenient sampling instead of random sampling technique was utilized. However the convenient sample became appropriate since there was no up-dated and current sample frame to randomly select the respondents.

Considering the population of these four ethnic groups in the country forming about $80 \%$ of the total population of the country a small sample size of 164 for the study might affect empirical generalizability of the findings. However, in qualitative study small sample size with reliable, trustworthy and valid data is considered adequate and acceptable for theoretical conclusions to be drawn (Cassell \& Walsh, 2004; Milward, Asumeng \& McDowall, 2010). In all, the present study successfully accomplished its purported aim and that the limitations encountered in it should be viewed as a challenge for future researchers to attempt.

\section{Conclusion}

Our study revealed that ethnic stereotypes persist in Ghana. Social identity to an extent explains the kind of stereotypes generated for in-group and out-groups. This is so, because not all in-group members used negative stereotypes to describe the out-group. In-group members likewise used negative stereotypes for the in-group. The contact hypothesis helped to understand such a departure from the traditions of social identity theory. This means ethnic prejudice could be reduced when the interaction among groups is more advocated. This could be achieved if adequate knowledge on how understanding each other could aid develop the nation becomes a key factor in our day to day activities because a consequence of stereotyping is discrimination. Discrimination could deprive qualified persons who fit for a job as a result of nepotism. Thus, members of various ethnic groups need to be educated on how positive inter-group interaction could help develop the nation. This implies that education whether formal or informal on embracing diversity through a nation building should be the optimal value of government in collectivist culture so that out-groups would be accepted which could reduce social inequality and thereby alleviating ethnic prejudice. 


\section{Refernce}

Barrett, M., Wilson, H., \& Lyons, E. (1999). Self-categorization theory and the development of national identity in English children. Poster presented at Biennial meeting of the society for research in children development. New Mexico, USA

Cassell, C., \& Walsh, S. (2004). "Analysing repertory grids”. In Cassell, C and Symon, G. (Eds), Essential Guide to Qualitative Methods in Organisational Research, Sage Publications, London. http://dx.doi.org/10.4135/9781446280119.n6

Castano, E., \& Yzerbyt, V. Y. (1998). The highs and lows of group homogeneity. Behavioral Process, 42, 219-238. http://dx.doi.org/10.1016/S0376-6357(97)00078-8

Condor, S. (2006). Public Prejudice as Collaborative Accomplishment: Towards a Dialogic Social Psychology of Racism. Journal of Community \& Applied Social Psychology, 16, 1-18. http://dx.doi.org/10.1002/casp.845

Ghana Statistical Service. (2012). 2010 Population and Housing census: Summary report of final results. Accra: Author.

Gordijn, E., Finchilescu, G., Brix, L., Wijnants, N., \& Koomen, W. C. (2004). The influence of prejudice and stereotypes on anticipated affect: feelings about a potentially negative interaction with another ethnic group. South African Journal of Psychology, 38(4), 589-601. http://dx.doi.org/10.1177/008124630803800401

Hogg, M. A., \& Reid, S. A. (2006). Social Identity, Self-Categorization, and the Communication of Group Norms. Communication Theory, 16, 7-30. http://dx.doi.org/10.1111/j.1468-2885.2006.00003.x

Hornsey, M. J. (2008). Social identity theory and self-categorization theory: A historical review. Social and Personality Psychology Compass, 2, 204-222. http://dx.doi.org/10.1111/j.1751-9004.2007.00066.x

Kawakami, K., Spears, R., \& Dovidio, J. E. (2002). Disinhibition of Stereotyping: context, prejudice, and target characteristics. European Journal of Social Psychology, 32, 517-530. http://dx.doi.org/10.1002/ejsp.106

Khanlou, N., Koh, J. G., \& Mill, C. (2008). Cultural Identity and Experiences of Prejudice and Discrimination of Afghan and Iranian Immigrant Youth. International Journal of Mental Health Addiction, 6, 494-513 http://dx.doi.org/10.1007/s11469-008-9151-7

Leeson, P. R. C. (2006). The role of social identities and individual differences on predicting prejudice: a plea for tolerance. Retrieved from http://ro.uow.edu.au/theses/134

Maxwell, J. A. (1992). Understanding and Validity in qualitative research. Harvard Educational Review, 62(3), 279-300

Miles, M. B. \& Huberman, A. M. (1994). Qualitative Data Analysis (2nd ed.). Thousand Oaks, C.A: Sage Publications. 
Millward, L. J., Asumeng, M., \& McDowall, A. (2010). "Catch me if you can?" A psychological analysis of managers' feedback seeking. Journal of Managerial Psychology, 25(4), 384-407. http://dx.doi.org/10.1108/02683941011035296

Nakamura, K. (2009). Students' Perceptions of Ethnicity and Learning: A case study of the United States International University. Journal of Language, Technology \& Entrepreneurship in Africa, 1(2), 76-89. http://dx.doi.org/10.4314/jolte.v1i2.41773

Newman, I., \& Benz, C. (1998). Qualitative-quantitative research methodology: Exploring the interactive continuum. Carbondale: Sothern Illinois University Press.

Oakes, P. (2001). The root of all evil in intergroup relations? Unearthing the categorization process. In R. Brown \& S. Gaertner (Eds.), Blackwell handbook of social psychology: Intergroup processes (pp. 3-21). Oxford, UK: Blackwell.

Oakes, P. J., Haslam, S. A., \& Turner, J. C. (1994). Stereotyping and Social Reality. Oxford: Blackwell.

Pettigrew, T. F. (1998). Intergroup Contact Theory. Annual Review Psychology, 49, 65-85. http://dx.doi.org/10.1146/annurev.psych.49.1.65

Pettigrew, T. F., \& Tropp, L. R. (2006). A meta-analytic test of intergroup contact theory. Journal of Personality and Social Psychology, 90, 751-783. http://dx.doi.org/10.1037/0022-3514.90.5.751

Stets, J. E., \& Burke, P. J. (2000). Identity theory and Social Identity theory. Social Psychology Quarterly, 63(3), 224-237. http://dx.doi.org/10.2307/2695870

Tajfel, H., Billig, M., Bundy, R., \& Flament, C. (1971). Social categorization and intergroup behavior. European Journal of Social Psychology, 1, 149-178. http://dx.doi.org/10.1002/ejsp.2420010202

Van Bavel, J. J., \& Cunningham, W. (2011). A social neuroscience approach to self and social categorization: A new look at and old issue. European Review of Social Psychology, 21, 237-284. http://dx.doi.org/10.1080/10463283.2010.543314 
Appendix 1. Coding system: positive and negative stereotypes

A. In-group perception

- Positive stereotypes

1. Human values

\begin{tabular}{|c|c|c|c|}
\hline Akan & Ewe & $G a$ & Dagomba \\
\hline Generous////////// & Hospitable// & Sociable/// & Humble/ \\
\hline Hospitable//////////////// & Compassionate////// & Accommodative/ & Trustworthy/ \\
\hline Sociable//// & Generous//////// & Humorous// & Compassionate// \\
\hline Accommodative/ & Academically & Compassionate// & Hospitable///////////////// \\
\hline Compassionate///// & inclined $/ / / / / / / / / / / /$ & Hospitable//////// & Wise/ \\
\hline Humorous / & Humble/ & Confident/ & Disciplined/ \\
\hline $\mathrm{Calm} / /$ & Accommodative/ & Peaceful/law-abiding// & Patient/ \\
\hline Responsible/ & Honest/// & Few are academics/ & Generous//////////// \\
\hline Selfless//// & Trustworthy/ & Tolerant/ & Peaceful// \\
\hline Trustworthy// & Disciplined/ & Not tribalistic/ & $\begin{array}{l}\text { Accommodative// } \\
\text { Determined/ } \\
\text { Honest// }\end{array}$ \\
\hline
\end{tabular}

2.Culture/Power

\begin{tabular}{|l|l|l|l|}
\hline Akan & Ewe & Ga & Dagomba \\
\hline Rich culture/// & Unique culture/// & Great culture/ & Unique culture/// \\
Unique culture//// & Best culture/// & Love for culture/ & $\begin{array}{l}\text { Norms are inculcated } \\
\text { in children// } \\
\text { Best cultural norms } \\
\text { and values///////// } \\
\text { Bonded/ }\end{array}$ \\
Superior/// & $\begin{array}{l}\text { Men of identity/ } \\
\text { Influential/ }\end{array}$ & & United/ \\
& & & \\
\hline
\end{tabular}

\section{Work ethics}

\begin{tabular}{|l|l|l|l|}
\hline Akan & Ewe & $G a$ & Dagomba \\
\hline Industrious/ & Industrious/ & Hard working/ & Industrious/ \\
Hardworking///// & Hardworking// & & Hardworking///// \\
Successful/ & $/ / / / / / / / / / /$ & \\
Creative/ & Creative/ & & \\
Problem solvers// & & & \\
Business oriented/ & & & \\
Optimistic/ & & & \\
Perseverance/ & & & \\
\hline
\end{tabular}


- Negative Stereotypes

\begin{tabular}{|l|l|l|l|}
\hline Akan & Ewe & Ga & Dagomba \\
\hline Proud///// & Tribalistic//////////// & Lazy/////// & Aggressive///// \\
Greedy// & Unfriendly////////// & Irresponsible////// & Impatient//////// \\
Boastful/ & Complicated and & Discriminate////// & Envious//// \\
Fearful/// & difficult to & Loud///// & \\
Some are evil/// & handle///// & Don't like school/// & \\
Demean others// & & Quarrelsome////// & \\
& & Unforgiving/// & \\
\hline
\end{tabular}

\section{B. Three In-groups'perception of a target Out-group}

Respondents also expressed their perception of their out-groups. In all, three target out-groups emerged. Akan as the target out-group for Dagomba, Ga and Ewe shows that the three ethnic groups talked about their perception of Akan.

\begin{tabular}{|l|l|}
\hline Positive Stereotype & Negative Stereotype \\
\hline Good people///////// & Discriminate//////////// \\
Truthful/ & Boastful////////// \\
Hospitable///// & Proud/////////// \\
Hardworking///////// & Greedy/ \\
Creative//// & No school// \\
Sociable/// & Talkative// \\
Educated// & \\
Responsible//// & \\
Very industrious//// & \\
Business oriented///////////////////// & \\
Trustworthy// & \\
Supportive/// & \\
\hline
\end{tabular}




\section{Macrothink}

Journal of Social Science Studies

ISSN 2329-9150

2015, Vol. 2, No. 1

Ewe was the second target out-group for Dagomba, Ga and Akan where the three groups also described how they think about Ewes.

\begin{tabular}{|l|l|}
\hline Positive Stereotype & Negative Stereotype \\
\hline Sociable///// & Hostile/////// \\
Generous//////// & Very lazy/ \\
Intelligent///// & Tribalistic////////// \\
Hardworking//////// & Bad people//// \\
Respectful//// & Difficult// \\
Religious//////// & Greedy///// \\
Patience/ & Boastful// \\
Caring/// & Unforgiving// \\
Educated////////// & Discriminate//////// \\
Law abiding/ & Unfriendly//// \\
Confident// & \\
Hospitable/// & \\
\hline
\end{tabular}

Ga also became the target out-group for the three in-groups Dagomba, Ewe and Akan.

\begin{tabular}{|l|l|}
\hline Positive Stereotype & Negative Stereotype \\
\hline Nice people//// & Lazy///////////// \\
Sociable/ & Aggressive///// \\
Achievers// & Discriminate/// \\
Grandiose/ & Violent// \\
Hospitable/// & Talkative// \\
Business oriented/ & Backbite// \\
Peaceful/ & Coward// \\
Generous/ & Quarrelsome/ \\
Boxers////////////// & Opportunist// \\
\hline
\end{tabular}




\section{Macrothink}

Journal of Social Science Studies

ISSN 2329-9150

2015, Vol. 2, No. 1

Lastly, Dagomba was the target out-group for Ga, Ewe and Akan where their perception was also gathered.

\begin{tabular}{|c|c|}
\hline Positive Stereotype & Negative Stereotype \\
\hline Hardworking////////////////////// & Suspicious///// \\
\hline Intelligent/// & Low self-esteem////////////////// \\
\hline Uphold tradition///// & Aggressive///////////////////////////////// \\
\hline Hospitable///// & Difficult///////////// \\
\hline Sociable////////////// & \\
\hline Generous/ & \\
\hline Educated/// & \\
\hline Peaceful/ & \\
\hline Law abiding/ & \\
\hline Respectful/ & \\
\hline Industrious//// & \\
\hline Trustworthy/// & \\
\hline
\end{tabular}

\section{Copyright Disclaimer}

Copyright reserved by the author(s).

This article is an open-access article distributed under the terms and conditions of the Creative Commons Attribution license (http://creativecommons.org/licenses/by/3.0/). 